\title{
Recent Research on Gravitational Waves
}

\author{
G. Pizzella, Rome
}

(Guglielmo Marconi Institute of Physics)

Joseph Weber began, in 1958, to examine the possibility of detecting the gravitational waves predicted by Einstein in 1916 in his theory of general relativity. Although the calculations showed that, in Einstein's words, the gravitational irradiated power "in all thinkable cases must have a practically vanishing value" it seemed to Weber that with modern techniques it should be feasible to detect gravitational waves such as those arising from catastrophic cosmic events (i.e. supernovae explosions or, more generally, gravitational collapse processes).

At present we can state that no gravitational waves have been detected with certainty, because the positive results reported by Weber since 1967 have not been confirmed by any other experimenter and, there- fore, this very fundamental problem is still awaiting a solution. Although the results were negative, it must be noted however, that no experimental group repeated exactly the Weber experiment and only one group which had tried to detect gravitational waves and failed decided to abandon the search. It is note-worthy that all the others are still pursuing the same goal with more sophisticated techniques but with most of the basic choices made by Weber for his experiment still preserved. The problem is thus far from being settled, and the scientific community believes that some very peculiar facts might emerge from this research.

In order to illustrate the present status, I shall divide the experiments into three categories: the experiments which have already been done, those which will give results within a relatively short time, those which are more speculative. To make a comparison between the various experiments it is necessary to introduce the idea of the sensitivity of a gravitational wave antenna. Consider a cylinder (Webertype) of mass $M$, length $L$ and, when loaded with the transducer, mechanical quality factor $Q$. The cylinder resonates at the frequency:

$$
v_{0}=\omega_{0} / 2 \pi=v / 2 L
$$

where $v$ is the velocity of sound in the cylinder (typically aluminium) when it interacts with a gravitational wave which has a non null Fourier component at $v_{0}$. A typical cryogenic Weber type gravitational antenna is very schematically shown in Fig. 1. The effect of the gravitational wave impinging perpendicularly to the cylinder's axis is to generate stresses along the

Table 1 - Experiments Already Performed

\begin{tabular}{|c|c|c|c|c|c|c|c|c|}
\hline $\begin{array}{l}\text { Research } \\
\text { Group }\end{array}$ & $\begin{array}{l}\text { Type of } \\
\text { Antenna }\end{array}$ & $\begin{array}{l}\text { Frequency } \\
(\mathrm{Hz})\end{array}$ & $\begin{array}{l}M \\
(\mathrm{~kg})\end{array}$ & $\begin{array}{l}T \\
(\mathrm{k})\end{array}$ & $\begin{array}{c}T_{\text {eff }} \\
(\mathrm{k})\end{array}$ & $\begin{array}{l}\text { Minimum } \\
\text { observable } \\
\text { Flux } S \text { (GPU) }\end{array}$ & $\begin{array}{l}\text { Remarks on } \\
\text { the Sensitivity }\end{array}$ & $\begin{array}{l}\text { Remarks on Occurrence } \\
\text { of Extra Pulses }\end{array}$ \\
\hline Maryland & $2 \mathrm{Al}$ cylinders & 1660 & 1500 & 293 & $\begin{array}{l}\text { not } \\
\text { meas. }\end{array}$ & $\begin{array}{l}6.7 \\
\text { (estimated) }\end{array}$ & $\begin{array}{l}\text { computed for } \\
\text { singles from } \\
\text { equivalent } \\
\text { circuit }\end{array}$ & $\begin{array}{l}\text { Coincidences above } 4 \text { standard } \\
\text { deviations have been observed } \\
\text { in certain periods in } 1973 \\
\text { and } 1974\end{array}$ \\
\hline Moscow & $2 \mathrm{Al}$ cylinders & 1640 & 1300 & 293 & 75 & 50 & $\begin{array}{l}\text { measured for } \\
\text { singles }\end{array}$ & $\begin{array}{l}20 \text { days of measurements in } \\
1972,10 \text { days in } 1973 . \\
\text { No extra coincidences. }\end{array}$ \\
\hline I.B.M. & $1 \mathrm{Al}$ cylinder & 1637 & 480 & 293 & 18.5 & 34 & measured & One extra pulse in 27 days \\
\hline $\begin{array}{l}\text { Bell Tel.- } \\
\text { Rochester }\end{array}$ & $2 \mathrm{Al}$ cylinders & 710 & 3700 & 293 & 18.3 & 4.4 & $\begin{array}{l}\text { measured for } \\
\text { the coincidences }\end{array}$ & $\begin{array}{l}\text { Very few extra coincidences } \\
\text { in } 87 \text { days. }\end{array}$ \\
\hline $\begin{array}{l}\text { Frascati- } \\
\text { Munich }\end{array}$ & $2 \mathrm{Al}$ cylinders & 1654 & 1560 & 293 & 7.3 & 4.0 & measured & $\begin{array}{l}350 \text { days of measurements in } \\
\text { coincidence. No pulse greater } \\
\text { than } 100 \text { GPU. Less than } 1.7 \cdot 10^{4} \\
\text { pulses greater than } 10 \mathrm{GPU} \text {. }\end{array}$ \\
\hline Meudon & 1 Al cylinder & 1635 & 1600 & 293 & 15 & 8.4 & computed & Data not available \\
\hline Glasgow & $\begin{array}{l}2 \text { Al double } \\
\text { cylinders }\end{array}$ & 1100 & 300 & 293 & 20 & 59 & measured & $\begin{array}{l}\text { One extra coincidence } \\
\text { in } 7 \text { months }\end{array}$ \\
\hline Reading & $\begin{array}{l}2 \text { Al double } \\
\text { cylinders }\end{array}$ & 1181 & 625 & 293 & 100 & 140 & measured & No extra coincidences \\
\hline Tokyo & 2 Al cylinders & 145 & 1400 & 293 & 10 & 1900 & measured & $\begin{array}{l}\text { No significant } \\
\text { extra coincidences }\end{array}$ \\
\hline Rome & $1 \mathrm{Al}$ cylinder & 8600 & 20 & 4.2 & 0.94 & 41 & measured & $\begin{array}{l}\text { Very few extra pulses } \\
\text { in a few days }\end{array}$ \\
\hline Stanford & $1 \mathrm{Al}$ cylinder & 1315 & 680 & 4.4 & 0.39 & 0.5 & measured & $\begin{array}{l}\text { Many extra pulses (noise) } \\
\text { in } 10 \text { hours }\end{array}$ \\
\hline Maryland & $1 \mathrm{Al}$ cylinder & 1755 & 130 & 8.1 & 0.5 & 3.4 & measured & Preliminary data \\
\hline
\end{tabular}




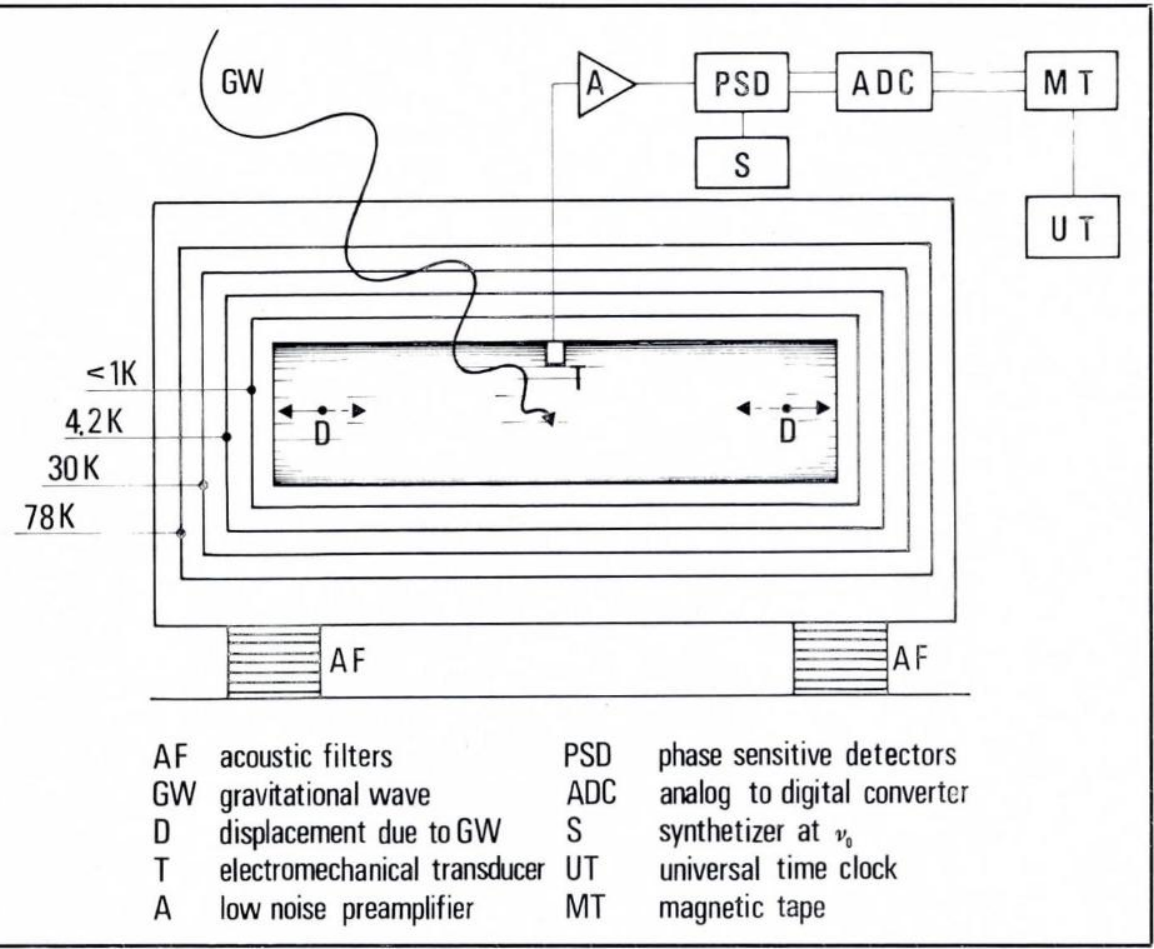

axis which put the cylinder into oscillation. The motion is detected with an electromechanical transducer, i.e. a piezoelectric ceramic. The sensitivity for short bursts (i.e. with duration $\left.\tau_{\mathrm{g}}<<Q / \omega_{\mathrm{o}}\right)$ of gravitational waves is defined by the relationship

$$
F\left(v_{o}\right)=\Sigma^{-1} k T_{\text {eff }} f
$$

where the various quantities are:

(a) $F\left(v_{0}\right)=$ minimum observable energy flux density (erg $\mathrm{cm}^{-2} \mathrm{~Hz}^{-1}$ ).

(b) $\quad \Sigma=(8 / \pi)(G / c)(v / c)^{2} M$

the integral cross section for a linearly polarized wave impinging perpendicular to the antenna axis. $G$ is the Newton constant and $c$ the velocity of light.

(c) $T_{\text {eff }}=T_{B}\left(\omega_{0} \Delta t\right) / Q+T_{t}$

the effective temperature obtained with proper data treatment which can be considered as made of two parts: the first due to the antenna thermal motion, the second to the transducer which converts the antenna mechanical vibrations into an electrical signal. The first depends on the antenna thermodynamical temperature $T_{B}$, on the sampling time $\Delta t$ and on the quality factor $Q$. The second $\left(T_{t}\right)$ depends on the transducer properties, on the electromechanical coupling to the bar and on the sampling time. The value of $T_{\text {eff }}$ can be reduced by employing $n$ antennas in coincidence. For $n$ identical antennas, $T_{\text {eff }}$ reduces by $n$. In this sense, the use of more antennas does not seem to improve considerably the sensitivity to gravitational waves. Actually the real gain of using coincidences is that spurious signals can be, with the coincidences, easily eliminated.

(d) The statistical factor

$$
f=2 \ln \Theta+\ln N_{0}-2 \ln N_{G}
$$
where $N_{0}$ is the number of samplings, $N_{G}$ the number of bursts which are observed each with energy density equal to or greater than $F\left(v_{0}\right), \vartheta$ indicates the number of standard deviations for the required confidence. Clearly this factor depends on the required statistics and only weakly on the antenna characteristics.

With the proper numerical constants for aluminium from eq. (2) we get what I will call reduced sensitivity i.e.

$$
S=F\left(v_{\circ}\right) / t=884 T_{\text {eff }} / M \text { GPU }
$$
where we have used the unit 1GPU = $10^{5}$ erg $\mathrm{cm}^{-2} \mathrm{~Hz}^{-1}$. 1.8 GPU is the flux density at the Earth due to the conversion of 1 solar mass in the centre of our Galaxy. If the conversion into gravitational wave energy is high, $1 \mathrm{GPU}$ is what we expect from a supernova explosion in our Galaxy.

\section{Experiments Already Performed}

The basic characteristics of the various experiments which have been performed up to now are shown in Table 1 (we quote only the most recent papers for each group). Beginning with the Weber experiment ') we recall that Weber observations started years earlier, with one antenna at first and then with two antennas in coincidence. Also, Weber has employed various shapes other than the cylinder, like a disk. In all cases, employing
Fig. 1 - Very schematic representation of a cryogenic Weber-type antenna. The measurements, amplitude and phase, are recorded on a magnetic tape for the data analysis with proper algorithms.

piezoelectric ceramics as electromechanical transducers, he has observed a number of coincidences well outside the statistical fluctuations. A weak point in his experiment, due certainly to its pioneering character, is the data analysis which is mostly done with analogue hardware that does not allow easily all the various steps of the data handling routine to be checked. For this reason the value of $T_{\text {eff }}$ is not given. In order to compute $S$ for Table 1 we have made use of the equivalent circuit parameters under the hypothesis that the data analysis has been performed in an optimal way, which may perhaps, overestimate somewhat the Weber sensitivity. Braginskii ${ }^{2}$ ) at the University of Moscow employed a similar apparatus except for the transducer which is based on measuring a capacity variation. Braginskii states he can observe a variation as small as one fourth of the Brownian noise which means $T_{\text {eff }}=$ $75 \mathrm{~K}$. The sensitivity, calculated with eq. (5), appears smaller than that computed for the Weber antenna.

A big step in improving the data analysis procedure was introduced by Garwin ${ }^{3}$ ) who recorded the information obtained from the electromechanical transducer, amplitude and phase, prior to the data treatment. In this way it is possible to obtain an experimental value of $T_{\text {eff }}$ and to do all the proper checks. However, due to the small mass of the antenna, the sensitivity calculated with eq. (5) is smaller than the theoretical one for Weber. Tyson at Bell Telephone, later on in coincidence with Douglass at Rochester, succeeded in building very sensitive antennas which operated in coincidence for a long period of time ${ }^{4}$ ). An inspection of the statistical distribution of the coincidence signals shows that only very few coincidences 
do not follow the distribution with $T_{\text {eff }}$ $=18.3 \mathrm{~K}$.

The Frascati-Munich group ${ }^{567}$ ) introduced a new method to couple the piezoelectric transducers to the bar, obtaining a rather low value for $T_{\text {eff }}$. Two antennas, one in Frascati (Italy) the other one in Munich (Germany) were operated in coincidence.

This experiment was run for 350 days during the period July 1973-January 1975 . There was no clear evidence for any excess coincidences at zero time delay and therefore upper limits to the gravitational radiation were given. These upper limits show that large gravitational wave pulses were not present during the time of measurement, but they do not rule out the possibility that many small pulses were due to gravitational radiation (see Table I).

Another experiment very similar to that of Weber has been performed at Meudon ${ }^{8}$ ) but so far the data have not been analyzed.

At Glasgow, Drever ${ }^{9}$ ) operated a new antenna originally suggested by Aplin ${ }^{10}$ ) for a faster response time consisting of two cylinders squeezed between a piezoelectric transducer. The results were negative but the sensitivity computed with eq. (5) is not high. Similar results with a similar antenna were also obtained by $\mathrm{Al}-$ len ${ }^{11}$ ) in Reading.

In Tokyo, Hirakawa ${ }^{12}$ ) has used an antenna of different shape, a square of aluminium with a cut on each side, in order to explore a different frequency region $(145 \mathrm{~Hz})$. The vibrations were detected by means of electrostatic transducers. Whilst $T_{\text {eff }}$ compared favourably with the other experiments, the sensitivity, which was not computed with eq. (5) but taken from reference (12) is very poor because, as the authors state, "the sensitivity is proportional to the square of the frequency and therefore is 100 times worse than that in the $\mathrm{kHz}$ region".
To complete the review of the room temperature experiments we recall also the work done by Aplin ${ }^{10}$ ) in Bristol and Maeder ${ }^{13}$ ) in Geneva. No positive results were obtained.

We come now to the low temperature experiments. The suggestion to use low temperature in order to reduce $T_{\text {eff }}$ came from Fairbank (Stanford) and Hamilton (Louisiana). A project was then started in collaboration with the University of Rome to construct 5 ton antennas operating at $3 \mathrm{mK}$. This project has not been terminated yet. In order to reach the final goal, smaller cryogenic antennas were realized and put into operation. The first cryogenic antenna to give reasonably good data was a small one $\left(20 \mathrm{~kg}\right.$ ) of the Rome group ${ }^{14}$ ) with $T$. $=2.1 \mathrm{~K}$ and later ${ }^{15}$ ) with $T_{\text {eff }}=0.94 \mathrm{~K}$. The Stanford ${ }^{16}$ ) group has put into operation a large antenna with $T_{\text {eff }}=$ $0.39 \mathrm{~K}$ and with a sensitivity of 0.5 GPU, the best sensitivity up to now. They observed very many pulses outside the expected statistical distribution. Since they concluded these pulses were due to mechanical noise and that their antenna could not be improved, they decided to stop working on it and proceeded with the construction of the $5000 \mathrm{~kg}$ antenna.

Finally the Maryland group also realized a cryogenic antenna ${ }^{17}$ ) but only very preliminary data are available today.

We must try now, even if tentatively, to reach some sort of conclusion about the existence or non-existence of gravitational waves which could explain the coincidences obtained by Weber (assuming the Weber sensitivity is what we quote in Table 1). A look at Table 1 shows that the only experiments which were really more sensitive that that of Weber, and which were run for a long period with all data properly analyzed were those of the Bell Telephone-Rochester and Frascati-Munich collaborations.
Neither experiment excludes the possibility that many small pulses could be due to gravitational waves with intensity of the order of 10-20 GPU. Weber claims he has used a very sensitive data analysis algorithm. Clearly, to solve this probem, one has to perform experiments with $s<1 \mathrm{GPU}$.

\section{Current Experiments}

We come now to the experiments which are under way and, first, we consider those which could produce data on a time scale of up to twothree years, as listed in Table II.

In Louisiana they are very near to cooling down the 5 ton antenna. They plan to use as transducer ${ }^{18}$ ) superconducting accelerometers based on radio frequency resonant circuits, modulated by the acceleration. At present they can detect displacements of $10^{-14} \mathrm{~cm}$ but in principle they can reach $10^{-20} \mathrm{~cm}$. Assuming that the first measurements will be made at $4.2 \mathrm{~K}$ they should be able to reach a sensitivity better than 1 GPU.

In Stanford also they are about ready to cool the 5 ton bar employing, as transducer, a resonating niobium diaphram. As a first step they could cool to $4.2 \mathrm{~K}$ and have $\mathrm{T}_{\text {eff }} \sim 10^{-3}$ which gives a very good sensitivity.

In Rome the work has progressed so far, to developing a $390 \mathrm{~kg}$ cryogenic antenna employing piezoelectric ceramics as transducers. Previous experience with the $20 \mathrm{~kg}$ antenna shows that these ceramics behave well at low temperature. However, the FET electronic amplifier which follows the transducer, will limit $T_{\text {eff }}$ to 0.1 at best. This antenna has been cooled down once to $4.2 \mathrm{~K}$ and is now being cooled down again.

A similar antenna of the Maryland group, already listed in Table I, which employs a resonant electrostatic capacitor as transducer, should also give useful data very soon.

Table II - Experiments Soon to Produce Results

\begin{tabular}{|c|c|c|c|c|c|c|c|}
\hline $\begin{array}{l}\text { Research } \\
\text { Group }\end{array}$ & $\begin{array}{l}\text { Type of } \\
\text { Antenna }\end{array}$ & $(\mathrm{Hz})$ & Transducer & $\begin{array}{l}T \\
(\mathrm{k})\end{array}$ & $\begin{array}{l}\text { Estimated } \\
T_{\text {eff }}^{(\mathrm{k})}\end{array}$ & $\begin{array}{l}M \\
(\mathrm{~kg})\end{array}$ & $\begin{array}{l}\text { Estimated } \\
\text { Sensitivity }\end{array}$ \\
\hline Louisiana & Al cylinder & 800 & $\begin{array}{l}\text { superconducting } \\
\text { accelerometers }\end{array}$ & 4.2 & $\left(10^{-14} \mathrm{~cm}\right)$ & 4800 & $<1$ \\
\hline Maryland & Al cylinder & 1755 & $\begin{array}{l}\text { resonant } \\
\text { capacitor }\end{array}$ & 4.2 & $3 \times 10^{-3}$ & 130 & 0.02 \\
\hline Moscow & $\begin{array}{l}\text { Sapphire } \\
\text { monocrystal }\end{array}$ & 30,000 & $\begin{array}{l}\text { Parametric } \\
\text { amplifier. }\end{array}$ & 1.4 & $\left(1.5 \times 10^{-15}\right) \mathrm{cm}$ & 1 & $<1$ \\
\hline Rochester & Silicon crystal & 19,000 & SQUID & 1.4 & $2 \times 10^{-3}$ & 4,9 & 0.13 \\
\hline Rome & Al cylinder & 1795 & Piezoelectric & 1.5 & 0.1 & 390 & 0.23 \\
\hline Stanford & Al cylinder & 800 & SQUID & 4.2 & $10^{-3}$ & 4800 & $2 \times 10^{-4}$ \\
\hline
\end{tabular}


Finally the Moscow and Rochester groups could succeed in obtaining good sensitivity by employing antennas based on a different philosophy which was first suggested by Braginskii. From eq. (4) it is seen that $T$, can be made smaller by increasing $Q$, but only if $T$ is not predominant. Thus, in such a case, one can use a smaller value of $M$, that is a smaller cross section $\Sigma$. The group in Moscow plans to use a saphire monocrystal and a parametric transducer based on the use of a high frequency superconductor e.m. resonator. At the moment they can detect bar vibrations as small as $1.510^{-15} \mathrm{~cm}$, but this sensitivity can be improved by improving the characteristics of the pumping generator for the parametric transducer. The group in Rochester plans to use, at present, a silicon crystal and, as transducer, a SQUID measuring the change in magnetic flux due to the displacement of a configuration with a very large flux gradient.

The experiments listed in Table II when properly working should solve, once for all, the problem raised by the Weber observations.

\section{Long Term Experiments}

We come now to the last part that includes all projects which aim to reach such high sensitivity that they go beyond the immediate goal, and establish, on the basis of the known facts of modern astrophysics, whether gravitational waves exist at all.

These experiments are listed in Table III. Again we find the LouisianaRome-Stanford collaboration with their 5 ton bars cooled to $3 \mathrm{mK}$. Assuming that the quantum limited sensitivity (due to the zero point energy of the bar-oscillator) can be reached, we have a sensitivity of $10^{-8} \mathrm{GPU}$ which will be a powerful tool for exploring the Universe. We then have the group in Perth ${ }^{19}$ ) which plans to use a 1 ton niobium bar in order to have both high $Q\left(\sim 10^{8}\right)$ and high $M(\sim 1$ ton $)$ and therefore do not need to go in the $\mathrm{mK}$ region. Among the groups who use the large $Q$ antennas we have also the Maryland and the Regina ${ }^{20}$ ) group. The Regina group, pioneer in measuring $Q$ at low temperature, unlike the other groups working on high $Q$ antennas, plans to reach temperatures in the $\mathrm{mK}$ range. The sensitivity limit for the high $Q$ antennas appears to be a little worse than that of the large $M$ antennas, but it is hard to figure out in advance all the problems which will certainly arise for all kinds of transducer.

In particular, the basic problem is
Fig. 2 - The $390 \mathrm{~kg}$ cryogenic gravitational wave antenna in Rome during assembly. The bar is tied by a cable to a copper container and will be levitated by means of a magnetic field.

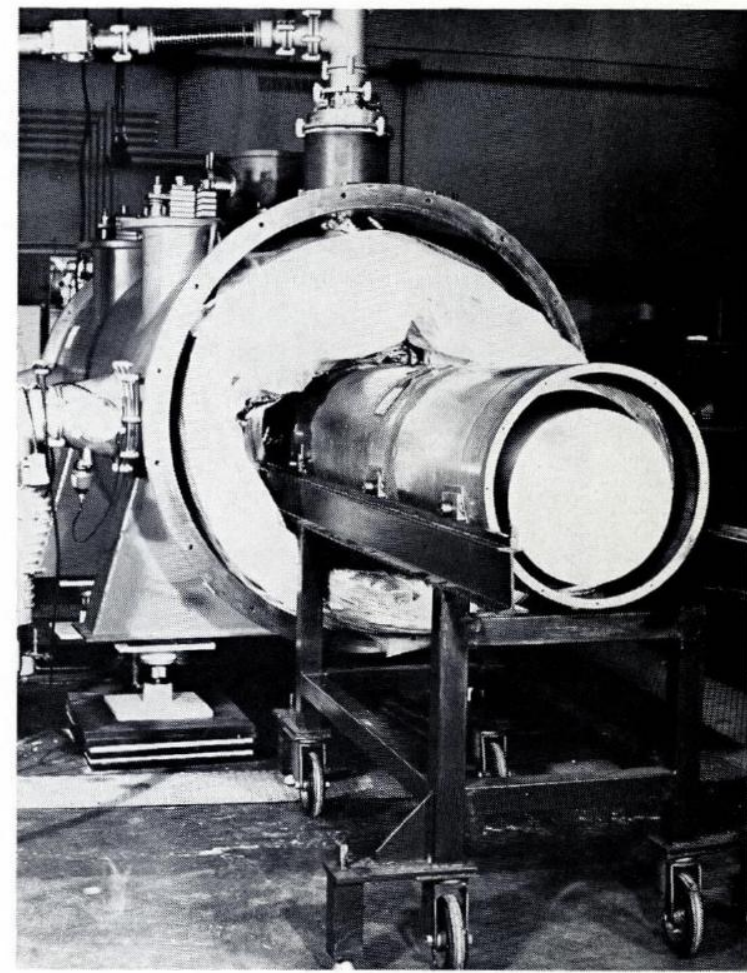

to have a transducer which does not disturb the vibrating bar $\left(T_{t}\right.$ negligible). Very interesting in this sense is a suggestion by Braginskii ${ }^{20}$ ) to measure directly the number of phonons in the fundamental mode of the bar, accepting that because of the uncertainty principle, there will be a large indeterminacy in the phase. Recently this problem has been investigated also by Thorne et al. ${ }^{21}$ ) who show a possible way to do it ("quantum nondemolition measurements").

Finally we consider the laser interferometers ${ }^{22,}{ }^{23}$ ). The principle of operation of these antennas, also suggested by Weber, is rather different from that of the previous ones. The instrument consists basically of a Michelson interferometer to measure the variation of the distance between two

points, that is the change in geometry due to the gravitational waves. Therefore it is a more direct way of measuring the properties of the space-time geometry and also has the advantage of being a wide-band detector. Unfortunately formidable difficulties have to be overcome before the sensitivity quoted in Table III due to the photon number fluctuation and therefore related to the laser power, is reached. Some are mechanical (how to suspend the mirrors), some are due to the residual vacuum (which changes the refractive index), some to the laser radiation pressure (which causes acceleration in the beam splitter), not to speak of the need to have a powerful and stable laser beam.

Because of all these problems the first experiment of this kind made at

Table III - Experiments for the Long-term

\begin{tabular}{|c|c|c|}
\hline $\begin{array}{l}\text { Type of } \\
\text { Antenna }\end{array}$ & Research Group & $\begin{array}{l}\text { Quantum Limited Minimum } \\
\text { Observable (GPU) } \\
\text { Flux }\end{array}$ \\
\hline $\begin{array}{l}\text { Large mass } \\
\text { ( } 5 \text { ton) }\end{array}$ & $\begin{array}{l}\text { Louisiana } \\
\text { Rome } \\
\text { Stanford }\end{array}$ & $10^{-8}$ \\
\hline $\begin{array}{l}M \sim 1 \text { ton } \\
Q \sim 10^{8}\end{array}$ & Perth & $10^{-7}$ \\
\hline $\begin{array}{l}\text { Large } Q \\
\text { (above } 10^{\circ} \text { ) }\end{array}$ & $\begin{array}{l}\text { Maryland } \\
\text { Moscow } \\
\text { Regina } \\
\text { Rochester }\end{array}$ & $10^{-6}$ \\
\hline $\begin{array}{l}\text { Laser interferometer } \\
(100 \text { Watt } \sim \mathrm{k} \mathrm{Hz})\end{array}$ & $\begin{array}{l}\text { Glasgow } \\
\text { M.I.T. } \\
\text { Munich }\end{array}$ & $\sim 10^{-8}$ \\
\hline
\end{tabular}


the Hughes Corporation ${ }^{24}$ ) had a sensitivity of roughly $1 \cdot 7 \cdot 10^{-13} \mathrm{~cm} / \mathrm{VHz}$ at $\sim 5 \mathrm{kHz}$ for an interferometer 850 $\mathrm{cm}$ long, which is equivalent to about $10^{3} \mathrm{GPU}$.

It is nevertheless possible that a network of very sensitive laser interferometers operating on base lines of many $\mathrm{km}$ be put into operation in space near the Earth in the distant future, telling us about all changes of the space time geometry which occur in the Universe.

\section{REFERENCES}

1. LEE, M, GRETZ, D, STEPPEL, $S$, and WEBER, J. "Gravitational Radiation Detector Observations in 1973 and 1974" Phys. Rev. D 19 (1976) 893.

2. BRAGINSKII, V.B., MANUKIN, A.B., POGOV, E.I., RUDENKO, V.N. and KHORER, A.A. "An Upper Limit on the Density of Gravitational Radiation of Extraterrestrial Origin" Sov. Phys. JETP 39 (1974) 387

3. LEVINE, J.L. and GARWIN, B.L. "New Negative Result for Gravitational Wave Detection and Comparison with Reported Detector" Phys. Rev. Lett. 33, (1974) 794. 4. DOUGLASS, D.H., GRAM, R.Q., TYSON, J.A. and LEE R.W. "Two Detector Coincidence Search for Bursts of Gravitational Radiation", Phys. Rev. Lett. 35 (1975) 480.

5. BILLING, H., KAFKA, P., MAISCHBERGER, K., MEYER, F. and WINKLER, W.

"Results on the Munich-Frascati Gravi- tational Wave Experiment" Lett. Nuovo Cimento 12 (1975) 111

6. BILLING, $H$. and WINKLER, W. "The Münich Gravitational Wave Detector" Nuovo Cimento 33B (1976) 665.

7. KAFKA, P. Proc. of the International School of Cosmology and Gravitation, Erice 1975, J. Weber ed. (Plenum Press, New York) 1977.

8. BONNAZZOLA, S. CHEVRETON, M., FELENBOK, P., HERPE, G. and THIERRYMIEG, J. "Meudon Gravitational Radiation Detection Experiment" Colloques Internationaux C.N.R.S. N. 220, June 1973 (Paris).

9. DREVER, B.W.P., HOUGH, J., BLAND, B. and LESSNOFF G.W. "Search for Short Bursts of Gravitational Radiation" Nature 246 (1973) 340.

10. APLIN, P.S. "An Improved Detector of Gravitational Radiation" GRG 3111 (1972). 11. ALLEN, W.D. and CHRISTODOULIDES, C. "Gravitational Radiation Experiments at the University of Reading and the Rutherford laboratory" J. Phys. A. Math. Gen. 8 (1975) 1726

12. HIRAKAWA, $H$. and NARIHARA, K. "Search for Gravitational Radiation at 145 Hz" Phys. Rev. Lett. 35 (1975) 330. 13. MAEDER, D.G. and SANDERSON, B., "Sensitivity Calibration and Electronic Simulation of Gravitational Burst Detectors" J. Phys. E Sci. Instr. 8 (1975) 920. 14 PIZZELLA, G., Report at the 4th Soviet gravitational Conference, Minsk, June 1976.

15. AMALDI, E. et al. "The Cryogenic Gravitational Wave Experiment in Rome: Progress Report, Sept. 1977" Nota Interna n. 697,18 novembre 1977, Istituto di Fisica, Roma.

16. BOUGHN, S.P. et al. "Observation of
Mechanical Nyquist Noise in a Cryogenic Gravitational Wave Antenna" Phys. Rev. Lett. 38 (1977) 454.

17. DAVIS, W., GRETZ, D., RICHARD, J.P. and WEBER, J., "Development of Cryogenic Gravitational Wave Antennas at the University of Maryland" Report at GR8, Waterloo, Aug. 1977.

18. OELFKE, W.C. and HAMILTON, W.O., "Superconducting Accelerometers for the Study of Gravitation and Gravitational Radiation" XXVII Congress, IAF, California, October 1976.

19. RAND, R.E, and BLAIR, D.G "The Gravitational Wave Project at the University of Western Australia" Australian Physicist 14 (1977) 132 and 151.

20. BRAGINSKII, V. B. and VORONTSOV, Yu. I. Usp. Fiz Nauk 114, 41 (1974) (Sov. Phys.-Usp. 17 644, 1975).

21. THORNE, K.S. et al. "Quantum Nondemolition Measurements of Harmonic Oscillators" Submitted to Phys. Rev. Letters (1978).

22. BARTON, R. J., PAPINI, G., RAMADAM, B., STRAYER, D. and TWARD, E. "Cryogenic Gravitational Wave Detector using Single Crystals" Proc. Symposium on Experimental Gravitation, Pavia, September 1976.

23. WEISS, R. Quarterly Progress Report, Research Lab. of Electronics MIT 105, 54 (1972).

24. WINKLER, W. "A Laser Interferometer to Search for Gravitational Waves" Proc. Symposium on Experimental Gravitation, Pavia, September 1976.

25. FORWARD, R.L., and MOSS, G.E. "Wideband Interferometric Gravitational Radiation Antenna" Meeting American Physical Soc., Los Angeles, Cal. December 1972.

\section{Neutron Scattering Experiments and New Theoretical Approaches}

The 7th Europhysics Conference on Macromolecular Physics was held in Strasbourg from May 23 to 26 . Despite the crowded calendar of meetings on polymer science, the EPS conferences have assumed an important role as they are dealing, on a European level, with well defined topics of current interest. The self-imposed restriction in the scope of the conference theme as well as the active international participation are advantages which permit a highly intensive coverage. At the same time they circumvent the problems of many large international conferences (numerous and short presentations in parallel sessions) or of national meetings (limited number of contributions in a particular area).

Following the first meeting of the Macromolecular Physics Section in 1973 , these topical EPS conferences have come to be considered by experts in the specialized fields as a forum for intensive discussions and for an exchange of latest results. The meetings are also attended, however, by the general polymer physicist who merely wishes to obtain refined information on e.g. structure or mobility. Europhysics Conference Abstracts are also increasingly used as a suitable, fast, and up-to-date reference to recent European progress in a particular field.

The above rather general remarks have been made as they both characterize the intentions of the Section and apply to the Conference in Strasbourg. There, 115 participants followed 8 main lectures and 32 contributed papers. Whereas these figures are quite typical for the size and programme organization of the EPS Polymer meetings it is regretted that there was no participation by eastern European countries, possibly due to the fact that neutron scattering activities in these countries are on a relatively low level.
In his report on quasi-elastic and inelastic scattering J. Higgins (London) reviewed the information on molecular motion to be obtained from the variation of coherent and incoherent scattering cross-sections with neutron wave vector $\pi$. She stated that in bulk rubbery samples, well above their glass transition temperatures, a fast segmental motion had been observed. Although the motion is somewhat slower than that in dilute solution, it is many orders of magnitude faster than translational diffusion of the whole molecule. In that case the Rouse model of normal modes for a "bead-spring" chain gave a surprisingly good fit to the data and the full energy width of the observed scattering law varies as $x^{n}$ with $3<n<4$ in most cases. The value of $n$ increased with temperature and with chain flexibility with an apparent upper limit of 4. Her lecture gave an excellent introduction into this area. Using this presentation as an example 